\title{
Knee-jerk response
}

What are we to make of the dispute between Immune Response (Carlsbad, CA) and academic researchers over the publication of unfavorable clinical trial data on the company's anti-HIV vaccine Remune? On the face of it - at least, on the face presented in the press - corporate bad boys have once again tainted the scientific ideal of open publication and free exchange of data. But when is it reasonable for academics to expect total freedom over the data they have gathered on a company's behalf, particularly if they have signed a confidentiality agreement?

In the latest spat, Immune Response is alleged to have suppressed the publication of the results of a phase III clinical endpoint trial evaluating the immune-based therapy Remune in AIDS patients receiving other anti-HIV therapies. According to the trial's lead researcher, Joseph Kahn of the University of California (San Francisco), he and Stephen Lagalos of Harvard University set about preparing a paper following termination of the trial, when an independent Data Safety Monitoring Board decided that Remune was no more effective than a placebo at reducing disease progression. The researchers told the company they were intending to submit the paper for publication in the Journal of the American Medical Association (see story on p. 1235).

At that point, according to Kahn, Immune Response "refused to release" all the data from the trial, it rejected requests for a list of the investigators involved in the trial, and it attempted to suppress pub- lication of the data. Immune Response's vice president Ronald Moss, naturally enough, tells a different story. The company, he says, is an "ardent supporter" of public disclosure of research findings. It had made no secret of premature termination of the Remune trial: indeed, it put out a press release in May 1999. It fully intended to publish the Remune data once "all parties, including clinical trial investigators, had input on what would be published," and merely wanted to include more detailed statistical analysis of a subset of patients, which (no surprise here) shows that Remune is beneficial to clinical outcome and effective in decreasing "viral load."

So, Immune Response wanted to apply some corporate "spin"not perhaps a tactic designed to win much sympathy among scientists. On the other hand, the researchers in this case have hardly been beacons of probity. For instance, one clinical investigator outside of the company is also voicing concerns that Kahn did not give him the opportunity to review and agree on the manuscript before submission.

In the end, although blanket gags may be unreasonable, so too, is disregard for some of the essential components of corporate structure. Researchers who take the corporate coin have to realize that the coin comes with a history that cannot be ignored. Some may need to show a little more respect for all of the requirements that confidentiality clauses imply.

\section{Therapeutic space invaders}

Life sciences used to be so simple. When money was scarce and knowledge was cheap, everybody seemed to know his or her place in what we might call "the therapeutic space." Pharma ran the clinical trials, and handled the sales and marketing; biotech did the more fundamental R\&D. Potential conflicts of interest were avoided by a gross delineation of the therapeutic space to which the collaboration applied. Thus a platform company could work with perhaps half a dozen or 10 pharmaceutical companies, each of which had exclusive rights to exploit the $R \& D$ in a particular, often very broad, therapeutic area.

Now, however, the erstwhile junior partners in the commercial dance are becoming considerably more assertive. In last year's HIV and hepatitis alliance between Abbott Laboratories and Triangle Pharmaceuticals, it is Triangle, for instance, not Abbott that is responsible for clinical development and interactions with the US regulatory authorities. In a much-publicized deal this year, Millennium Pharmaceuticals and Aventis will co-develop and co-market compounds in inflammatory diseases that spring from the collaboration. Millennium still gets "upfront" money-in the form of a \$250 million equity investment-and continuing payments for "technology transfer." But, as a partner in a joint venture, it receives no R\&D funding: its $\$ 1.2$ billion raised this year should help cover those costs. Furthermore, if compounds developed within the partnership prove effective outside inflammatory disease, however, it is Millennium, not Aventis, that has the right to exploit them.

Even more striking, though, is the deal that Vertex Pharmaceuticals (\$520 million raised this year) renegotiated with Aventis for the devel- opment of inhibitors of interleukin- $1 \beta$ converting enzyme (ICE), again in inflammatory diseases. Unconventionally, Aventis has no rights to other ICE inhibitors that Vertex subsequently develops. Vertex already has other lead candidates and is under no obligation to offer them to Aventis. Indeed, it is certainly arguable that it would be against Vertex's interests to do so. Aventis and other companies entering such deals, therefore, face a rather odd prospect. Assuming that all goes well, their shiny new compound with its novel mechanism of action will enter a welcoming and virginal marketplace. A few years after that, however, an improved compound with the same mechanism of action, and born of the same technological source, will join it, threatening its profitability.

This clearly creates a much more challenging commercial environment. Having disturbed the "natural ownership" implicit in traditional licensing deals, biotechnology companies will have to tread carefully around the sensitivities of big pharma. Their licensing strategy must allow second-generation compounds to have some intellectual property space in which to move. On the positive side (for biotechnology), pharmaceutical companies will have, perhaps for the first time, a real incentive to get newly licensed compounds into the marketplace quickly and more effectively. At the same time though, pharmaceutical managers will undoubtedly ask themselves just how much development risk they are really ready to assume for compounds that, five years on, may be only the third most effective drug intheir therapeutic area. 